BLS 32, No 2 2006. DOI: http://dx.doi.org/10.3765/bls.v32i2.3493

(published by the Berkeley Linguistics Society and the Linguistic Society of America)

\title{
A Feature Geometry of the Tongan Possessive Paradigm
}

\author{
CATHERINE MACDONALD \\ University of Toronto ${ }^{1}$
}

\section{Introduction}

Feature geometries adapted from Harley (1994) and others can be developed to account for the semantic distinctions in Tongan's massive possessive paradigm. These pronouns represent three distinct syntactic categories, and I propose a typology of these pronouns adapted from that proposed by Dechaine and Wiltschko (2002), in which each feature geometry is subsumed under a different syntactic head.

\section{The Tongan Pronominal Paradigms}

Tongan personal and possessive pronouns distinguish four persons and three numbers. In the possessive paradigm, the person and number features are those of the possessor, not the possessum. In addition, the possessive pronominal forms encode the definiteness of the possessum, speaker's sympathy, and the relationship between possessor and possessum. Sympathy is encoded through the incorporation of a diminutive marker. The relationship between possessor and possessum is marked by an incorporated genitive case-marker: ' $a$ or ' $o$.

\subsection{Typology of Personal and Possessive Pronouns}

There are two types of personal and three types of possessive pronouns in Tongan. Strong personal pronouns function like ordinary DPs. Clitic personal pronouns cross-reference or replace a strong pronoun which is a transitive or intransitive subject (A or $\mathrm{O}$ ); they occur adjacent to the tense-aspect marker. "Ordinary" possessive pronouns precede the possessum, require an NP complement, and encode all distinctions described above. Postposed (adjectival) possessive pronouns follow the possessum and do not encode definiteness or sympathy. Emphatic possessive pronouns occur alone (instantiating the possessor and the possessum) or precede the possessum; they are always specific and definite, but

\footnotetext{
${ }^{1}$ I wish to thank Diane Massam, my supervisor, and Elizabeth Cowper, my instructor. Both have provided helpful criticism and encouragement. The paper has been changed from the version presented at BLS 2006, taking into account comments of other delegates.
} 


\section{Catherine Macdonald}

never sympathetic. The paradigms of these pronouns are presented in the appendix.

\subsection{Morphology of Possessive Pronouns}

The morphology of Tongan possessive forms is strikingly transparent. Each form comes historically from the merger of a personal pronoun encoding the person and number of the possessor, a possessive case marker ( ' $a$ or ' $o$ ), a determiner ( $h a$ nonspecific or he specific), and optionally, a diminutive particle si'i ('small') denoting sympathy. The weak personal pronoun forms the basis of ordinary and postposed pronouns; the strong one forms the basis of emphatic pronouns.

\section{Feature Geometries}

\subsection{Person}

Personal and possessive pronouns in Tongan encode three persons: first inclusive, first exclusive, second, and third. Several proposals have been made for a geometric arrangement of person features in pronouns. Harley's (1994) proposal has been variously adapted by Harley and Ritter (2002) (henceforth, H\&R), Cowper and Hall (2005), and McGinnis (2004). I adopt the strict hierarchical structure of Harley's (1994) model but H\&R's features.

In this analysis, first and second persons (discourse participants) are distinguished from other pronominal referents by a feature PARTICIPANT. Among discourse participants, parties including the speaker (first person) are distinguished from those not including the speaker (second person) by the presence of SPEAKER. An inclusive/exclusive distinction is made by the presence of ADDRESSEE under SPEAKER. This feature is not present in the second person, even though its referent is an addressee, because the feature is available only when contrastive, i.e. when it distinguishes one possible referent from another. The geometry is given in (1).

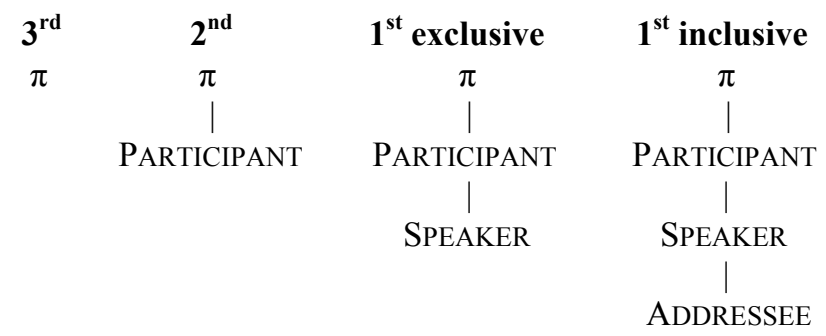

\subsection{Number}

Personal and possessive pronouns in Tongan distinguish singular, dual, and plural. The feature hierarchy proposed by Harley (1994) has been adapted by H\&R, Cowper (2003, 2005), and McGinnis (2004). Again, I adopt the geometry of Harley (1994) with H\&R's features. INDIVIDUATION distinguishes between mass and countable entities. Its dependent, PlURAL, distinguishes non-singular from singular referents. In a three-way number system, PLURAL has a dependent, 


\section{Feature Geometry of Tongan Personal Pronouns}

MINIMAL, which distinguishes "minimal groups" (i.e. groups of two) from others. Underlying this proposal is the assumption that dual is more marked than plural, based on Greenberg's (1963) observation that any language with a dual also has a plural. Dryer (2005) argues that appeals to this observation are vacuous; no language could logically make a singular-dual distinction without also making singular-plural and dual-plural distinctions. Rice (1999) notes that crosslinguistic markedness may not accurately diagnose featural markedness, noting that in phonology, central vowels are infrequent among the inventories of the world's languages, but minimally marked where they occur. Cowper $(2003,2005)$ argues that instead of a feature marking groups of two as minimal, there is one marking larger groups as " $>2$ ", and thus dual is more "marked" than plural.

Cowper (2003) argues that syncretisms should provide evidence: singular-dual syncretisms will support her model, and singular-plural syncretisms will support that of Harley (1994). In Tongan, due to the paucity of agreement morphology, there is little such evidence, and it is unhelpful. Churchward (1953) lists ten nouns with marked dual and/or plural forms: five display dual-plural syncretisms; three singular-dual syncretisms; one a singular-dual syncretism; and one has singular and plural forms, either of which can be used for dual.

An alternative source of evidence is the prenominal dual and plural markers, which seem to suggest that dual is more marked than plural. Nevins (2006:2), citing Jakobson and Greenberg, notes that "if a certain category is marked, then one will find fewer oppositions for other categories within it"; Tongan has one dual and seven plural markers. I thus adopt the geometry in (2).
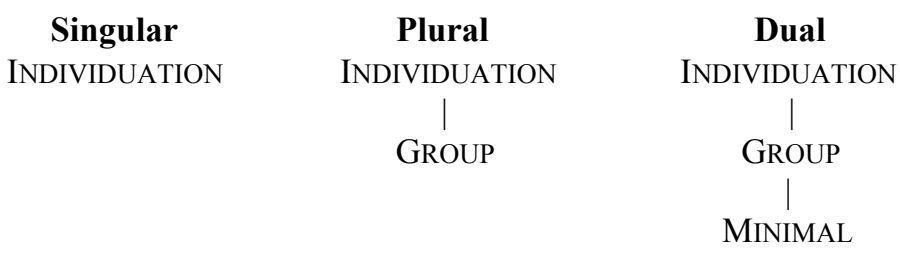

\subsection{Specificity and Diminutivity}

The morphological transparency of the Tongan possessive pronouns reveals the presence of the incorporated determiners he ('specific') or ha ('nonspecific') and their respective "emotional" counterparts si' $i$ and si' $a$. These four determiners arise from the four possible combinations of SPECIFIC and DIMINUTIVE.

Although he and $h a$ are usually glossed as 'a' and 'the', respectively, Dukes (2006) argues that 'specific' and 'nonspecific' are more accurate. Likewise, Churchward (1953), who defines he as 'semi-definite' and ha as 'completely indefinite', notes that the latter can be used with things whose existence is questioned or denied (cf. his $(7 \mathrm{c}, \mathrm{d})$ ). Hendrick (2005) points out that ha and he are equivalent to the two senses of English $a$ in the de dicto and de re readings of a sentence like Kim is looking for a newt in the garden, and that the equivalent of the is he plus the definitive accent, a stress shift targeting the final word in the definite DP (Churchward 1953, Dukes 1996, Hendrick 2005). It is only available 


\section{Catherine Macdonald}

with he or a specific possessive pronoun, not with $h a$. Specific and nonspecific possessives are shown in (3).
a. he'eku
helé
SPEC-POSS.A-1EX.SG knife
'the-my knife (the knife which is mine)'
b. ha'aku hele
NONSPEC-POSS.A-1EX.SG knife
'a-my knife (a knife which is mine)'
c. 'oku 'ikai ha'aku tohi.
PRES NEG NONSPEC-POSS.A-1EX book
'I haven't a book.' (lit. 'There is not a-my book.')

(Churchward 1953:130)

Clark (1974) argues that the definitive accent is the reflex of a demonstrative, * $a$. This clitic, having lost its phonological specification, is now a null mora affixed to the end of a DP, lengthening the final vowel and causing primary stress to be reassigned to it. In addition to its phonological specification, this clitic has lost meaning; it is now a "purely referential marker of definiteness" (Clark 1974:107).

Cowper and Hall (2003) propose the following geometry for determiner features: a D with no dependents is "nonspecific" (and indefinite). D may have a dependent SPECIFIC; it, in turn, may have a dependent DefinITE. Tongan determiners do not mark definiteness, so DEFINITE is not a D-feature in this language; it is the interpretation of a neutral demonstrative in $\mathrm{Dem}^{0}$. I will return to this with the syntax of emphatic possessive pronouns in $\S 3$.

Emotional import, encoded in "ordinary" possessive pronouns and determiners, is realized by an incorporated diminutive marker si'i ('small'). Its presence indicates the speaker's "feelings of affection, friendship, pity, humility, or respect" (Churchward 1953:23). Illustrative examples are presented in (4). I propose that the "emotional" feature is DimINUTIVE, a dependent of D. Since this is a sister to SPECIFIC, these features are independent, allowing all four possible combinations. The proposal is presented in (5).
a. kuo lavea si'a
PERF hurt NONSPEC.EMOT child
'Has a (dim.) child been hurt?'

b. 'oku nofo masiva si'eku PRES very poor SPEC.EMOT-POSS.A-1EX.SG parent

'My parents are very poor.'
(Churchward 1953:23)

mātu'á.

(Shumway 1971:513) 


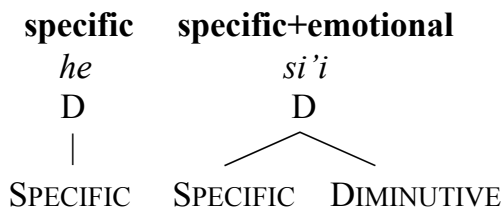

\subsection{Subjective vs. Objective Possession}

Tongan encodes two types of possession with the case-markers ' $a$ and ' $o$. It has been claimed that the choice of ' $a$ or ' $o$ has become rigidly lexicalized for most possessa, but Taumoefolau (1996) claims that while there may be a conventional preference for ' $a$ or ' $o$ with each noun, this can be overruled. Wilson (1982) argues that ' $a$ indicates possessor "control over the initiation of the possessive relationship", and 'o marks default possession. Others characterize the distinction as alienable/inalienable (Otsuka 2000) or subjective/objective (Churchward 1953). Moyse-Faurie (2000) argues that many factors contribute to the choice. It is difficult to know how to treat the feature(s) distinguishing ' $a$ and ' $o$ in Tongan.

It also needs to be determined which of ' $a$ or ' $o$ is marked. Although Wilson (1982) proposes that ' $a$ is marked, Clark (2000) notes that where languages have lost the ' $a$ /' $o$ distinction, ' $a$ has remained. This and the fact that ' $o$ only marks objects in nominalizations while ' $a$ marks both transitive and intransitive subjects suggest that ' $O$ is marked. I propose a feature ОВJЕCT dependent on a possessive head between the determiner and the possessor.

\section{Typology of Tongan Pronouns}

Dechaine and Wiltschko (2002) (henceforth D\&W) propose three types of pronominals: pro-DPs, pro- $\varphi$ Ps, and pro-NPs. Expanding their typology, I propose that the Tongan possessive pronouns are pro-DemPs ("emphatic"), pro-D ${ }^{0} \mathrm{~s}$ ("ordinary"), and pro-PossPs ("postposed"). Each realizes a different syntactic structure; the terminal nodes host its morphosyntactic features.

\section{1. "Ordinary" Possessive Pronouns}

"Ordinary" possessive pronouns in Tongan consist of a determiner, a possessive case-marker, and a pronominal root encoding the $\varphi$-features of the possessor. They are pro- $\mathrm{D}^{0} \mathrm{~s}$, taking the possessum NP as complement. Evidence that the pronoun and its complement NP constitute a DP comes from their distribution: they function as arguments (6), not as predicates. I propose the structure in (7).

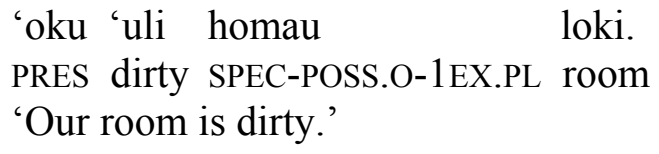




\section{Catherine Macdonald}

(7)

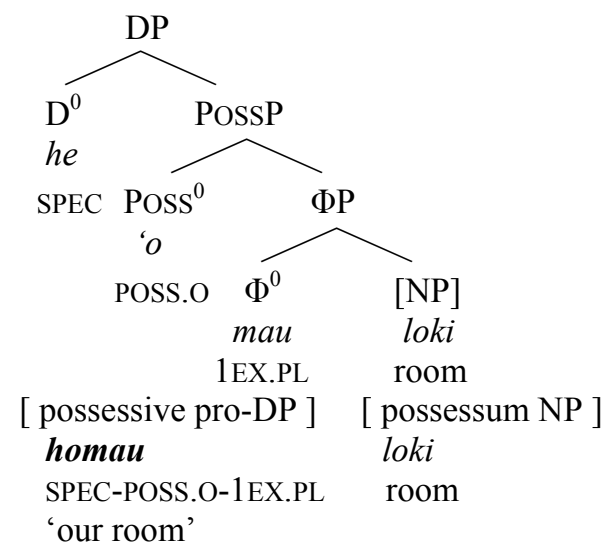

\subsection{Postposed Possessive Pronouns}

Postposed possessive pronouns are PossP modifiers of NP. They take no NP complement, but have a nominal component $-\varnothing$ in the singular, ua ('two') in the dual, and tolu ('three') in the plural — which stands for the possessor. Morphologically, they resemble pro- $\mathrm{D}^{0} \mathrm{~s}$ without a determiner; they do not encode definiteness or sympathy. Syntactically, they behave like adjectives (8). They are predicative (8a) and attributive (8b): when attributive, they are postnominal; when predicative, they may be nominalized. Their structure is given in (9).
a. 'oku 'ana
eni.

PRES POSS.A-3SG this

'This is his.'

(Churchward 1953:135)

b. 'oku 'ikai ke u sai'ia he'ene founga 'ana. PRES NEG C 1EX.SG like SPEC-POSS.A-3SG method POSS.A-3SG 'I don't like his particular method.'

(Shumway 1971:434)

(9)

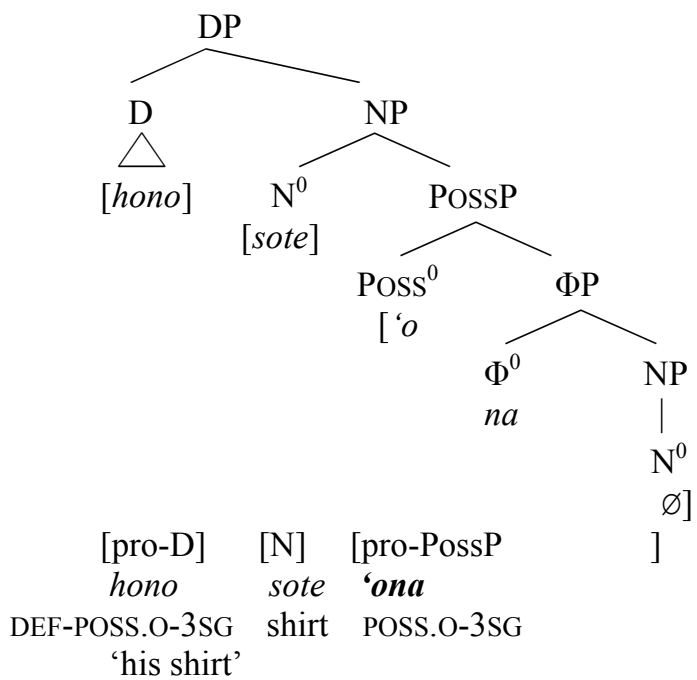




\subsection{Emphatic Possessive Pronouns}

Emphatic possessive pronouns are pro-DemPs, fully saturated with a null NP representing the possessum. Evidence for this saturation comes from their ability to occur as an argument (10) and the requirement that they bear the "definitive accent" which targets the right edge of DPs. The fact that they are always specific and never emotional, I propose, has to do with the selectional restrictions of Dem ${ }^{0}$. I propose the structure in (16).

'omi ha'akú.

bring POSS.SUBJ.1EX.SG

'Bring mine.'

(Churchward 1953:135)

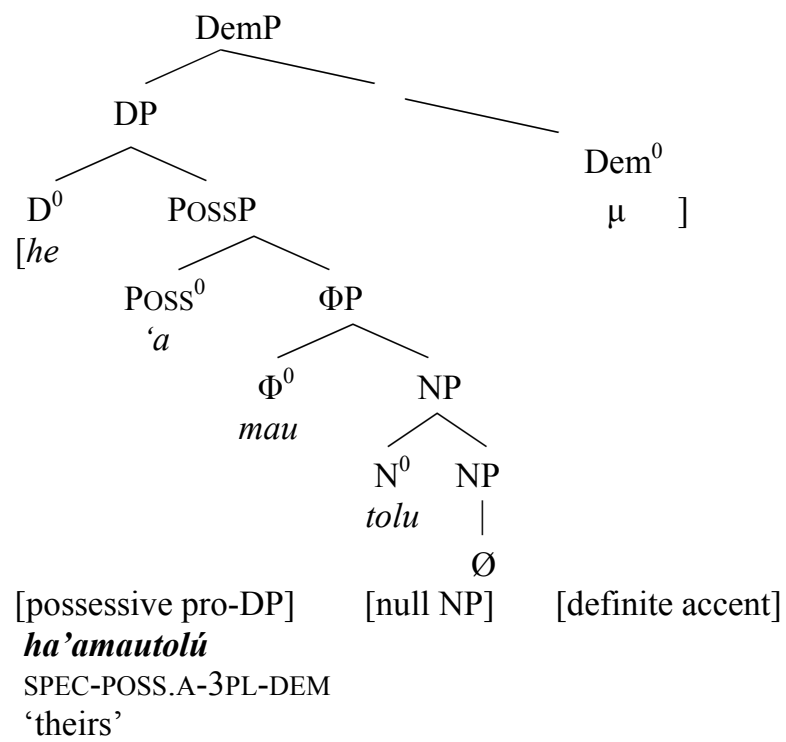

\section{Conclusions}

Tongan's rich possessive paradigm can be accounted for with a feature geometry adapted from those of Harley (1994) and Cowper and Hall (2003), to which I add DiminutiVE and ОвJест. These feature hierarchies are subsumed under syntactic terminal nodes. I adopt D\&W's proposal that "pronouns" represent a range of syntactic structures, adding pro-DemPs, pro- $\mathrm{D}^{0} \mathrm{~s}$, and pro-PossPs to their inventory. Evidence for these structures comes from the morphology of Tongan possessive pronouns, as well as from the features available for each pronominal series and their syntactic behaviors.

\section{References}

Churchward, C. Maxwell. 1953. Tongan Grammar. Nuku'alofa: Vava'u Press.

Clark, Ross. 1974. On the Origin of the Tongan Definitive Accent. Journal of the 


\section{Catherine Macdonald}

Polynesian Society 83:103-108.

Clark, Ross. 2000. Possessive Markers in Polynesian Languages. In Steven R. Fischer, ed., Possessive Markers in Central Pacific Languages: Sprachtypologie und Universalienforschung 53(3/4):258-268.

Cowper, Elizabeth. 2003. Why Dual Is Less Marked than Plural. Ms., University of Toronto. http://www.chass.utoronto.ca/ cowper/Whydual.pdf.

Cowper, Elizabeth. 2005. A Note on Number. Linguistic Inquiry 36(3):441-455.

Cowper, Elizabeth, and Daniel Currie Hall. 2003. The Syntactic Manifestation of Nominal Feature Geometry. Proceedings of Canadian Linguistics Association. Montreal: Cahiers Linguistiques de l'UQAM.

Cowper, Elizabeth, and Daniel Currie Hall. 2005. The Pieces of Pi. In MarieOdile Junker, Martha McGinnis, and Yves Roberge, eds., Proceedings of the 2004 Canadian Linguistics Association Annual Conference.

Dechaine, Rosemarie, and Martina Wiltschko. 2002. Decomposing Pronouns. Linguistic Inquiry 33(3):409-442.

Dryer, Matthew. 2005. Vacuous Appeals to the Number Hierarchy. Paper presented at the $6^{\text {th }}$ Biennial Meeting of ALT, Padang, Indonesia.

Dukes, Michael. 1996. On the Nonexistence of Pronominals and Anaphors in Tongan. Ph.D. diss., University of California at Los Angeles.

Fischer, Steven R. 2000a. Introduction. In Steven R. Fischer, ed., Possessive Markers in Central Pacific Languages: Sprachtypologie und Universalienforschung 53(3/4):229-250.

Harley, Heidi. 1994. Hug a Tree: Deriving the Morphosyntactic Feature Hierarchy. MIT Working Papers in Linguistics 21:289-320.

Harley, Heidi, and Elizabeth Ritter. 2002. Person and Number in Pronouns: A Feature-Geometric Analysis. Language 78(3):482-525.

McGinnis, Martha. 2004. On Markedness Asymmetries in Person and Number. Language 81(3):699-718.

Nevins, Andrew. 2006. Dual Is Still More Marked than Plural. Syracuse University Colloquium Series. http://ling.auf.net/lingBuzz000235.

Otsuka, Yuko. 2000. Ergativity in Tongan. Ph.D. diss., Oxford University.

Rice, Keren. 1999. Featural Markedness in Phonology: Variation - Part 1. GLOT International 4(7):3-6.

Shumway, Eric B. 1971. Intensive Course in Tongan. Honolulu: University of Hawai'i Press.

Taumoefolau, Melenaite. 1996. Nominal Possessive Classification in Tongan. In John Lynch and Fa'afo Pat, eds., Oceanic Studies: Proceedings of the First ICOL. Pacific Linguistics Series C, No. 133: 293-304.

Wilson, William H. 1982. Proto-Polynesian Possessive Marking. Pacific Linguistics Series B, No. 85. Canberra: Australian National University. 
Catherine Macdonald

Department of Linguistics

University of Toronto

130 St. George Street, Room 6076

Toronto, Ontario M5S 3H1

Canada

cath.macdonald@utoronto.ca

\section{Appendix: Paradigms of Tongan Personal and Possessive Pronouns}

\section{Personal Pronouns}

\begin{tabular}{|l|l|l|l|}
\hline \multicolumn{2}{|l|}{ Personal } & Strong & Weak \\
\hline \multirow{4}{*}{$1^{\text {st }}$ exclusive } & Singular & au & ku \\
\cline { 2 - 4 } & Dual & kimaua & ma \\
\cline { 2 - 4 } & Plural & kimautolu & mau \\
\hline \multirow{5}{*}{$1^{\text {st }}$ inclusive } & Singular & kita & te \\
\cline { 2 - 4 } & Dual & kitaua & ta \\
\cline { 2 - 4 } $2^{\text {nd }}$ & Plural & kitautolu & tau \\
\hline \multirow{5}{*}{$3^{\text {rd }}$} & Singular & koe & ke \\
\cline { 2 - 4 } & Dual & kimoua & mo \\
\cline { 2 - 4 } & Plural & kimoutolu & mou \\
\hline & Singular & ia & ne \\
\cline { 2 - 4 } & Dual & kinaua & na \\
\cline { 2 - 4 } & Plural & kinautolu & nau \\
\hline
\end{tabular}




\section{Catherine Macdonald}

\section{Ordinary Possessives}

\begin{tabular}{|c|c|c|c|c|c|}
\hline \multirow{2}{*}{\multicolumn{2}{|c|}{ Ordinary Possessive ('a) }} & \multicolumn{2}{|l|}{ Neutral } & \multicolumn{2}{|c|}{ Sympathetic } \\
\hline & & \multirow{2}{*}{\begin{tabular}{|l|} 
Definite \\
$h e^{\prime} e k u$ \\
\end{tabular}} & \multirow{2}{*}{$\begin{array}{l}\text { Indefinite } \\
\text { ha'aku }\end{array}$} & \multirow{2}{*}{\begin{tabular}{|l|} 
Definite \\
si'eku \\
\end{tabular}} & \multirow{2}{*}{\begin{tabular}{|l} 
Indefinite \\
si'aku
\end{tabular}} \\
\hline & Singular & & & & \\
\hline $1^{\text {st }}$ exclusive & Dual & he'ema & ha'ama & si'ema & si'ama \\
\hline & Plural & he'emau & si'emau & ha'amau & si'amau \\
\hline \multirow{3}{*}{$1^{\text {st }}$ inclusive } & Singular & he'ete & ha'ate & si'ete & si'ate \\
\hline & Dual & he'eta & ha'ata & si'eta & si'ata \\
\hline & Plural & he'etau & ha'atau & si'etau & ha'atau \\
\hline \multirow{3}{*}{$2^{\text {nd }}$} & Singular & ho'o & ha'o & si'o & si'ao \\
\hline & Dual & ho'omo & ha'amo & si'omo & si'amo \\
\hline & Plural & ho'omou & ha'amou & si'omou & si'amou \\
\hline \multirow{3}{*}{$3^{\text {rd }}$} & Singular & he'ene & ha'ane & si'ene & si'ane \\
\hline & Dual & he'ena & si'ena & ha'ana & si'ana \\
\hline & Plural & he'enau & si'enau & ha'anau & si'anau \\
\hline \multirow{2}{*}{\multicolumn{2}{|c|}{ Ordinary Possessive ('o) }} & \multicolumn{2}{|l|}{ Neutral } & \multicolumn{2}{|c|}{ Sympathetic } \\
\hline & & Definite & Indefinite & Definite & Indefinite \\
\hline \multirow{3}{*}{$1^{\text {st }}$ exclusive } & Singular & hoku & haku & si'oku & si'aku \\
\hline & Dual & homa & hama & si'oma & si'ama \\
\hline & Plural & homau & hamau & si'omau & si'amau \\
\hline \multirow{3}{*}{$1^{\text {st }}$ inclusive } & Singular & hoto & hato & si'oto & si'ato \\
\hline & Dual & hota & hata & si'ota & si'ata \\
\hline & Plural & hotau & hatau & si'otau & si'atau \\
\hline \multirow{3}{*}{$2^{\text {nd }}$} & Singular & ho & hao & si'o & si'ao \\
\hline & Dual & homo & hamo & si'omo & si'amo \\
\hline & Plural & homou & hamou & si'omou & si'amou \\
\hline \multirow{3}{*}{$3^{\text {rd }}$} & Singular & hono & hano & síono & si'ano \\
\hline & Dual & hona & hana & si'ona & si'ana \\
\hline & Plural & honau & hanau & si'onau & si'anau \\
\hline
\end{tabular}




\section{Postposed Adjectivals}

\begin{tabular}{|l|l|l|l|}
\hline Postposed (Adjectival) ('a) & Singular & Dual & Plural \\
\hline $1^{\text {st }}$ Exclusive & 'a'aku & 'amaua & 'amautolu \\
\hline $1^{\text {st }}$ Inclusive & 'a'ata & 'ataua & 'atautolu \\
\hline $2^{\text {nd }}$ & 'a'au & 'amoua & 'amoutolu \\
\hline $3^{\text {rd }}$ & 'a'ana & 'anaua & 'anautolu \\
\hline Postposed (Adjectival) ('o) & Singular & Dual & Plural \\
\hline $1^{\text {st }}$ Exclusive & 'o'oku & 'omaua & 'omautolu \\
\hline $1^{\text {st }}$ Inclusive & 'o'ota & 'otaua & 'otautolu \\
\hline $2^{\text {nd }}$ & 'o'ou & 'omoua & 'omoutolu \\
\hline $3^{\text {rd }}$ & 'o'ona & 'onaua & 'onautolu \\
\hline
\end{tabular}

\section{Emphatic Possessives}

\begin{tabular}{|l|l|l|l|}
\hline Emphatic Possessive ('a) & Singular & Dual & Plural \\
\hline $1^{\text {st }}$ Exclusive & ha'aku & ha'amaua & ha'amautolu \\
\hline $1^{\text {st }}$ Inclusive & ha'ata & ha'ataua & ha'atautolu \\
\hline $2^{\text {nd }}$ & ha'au & ha'amoua & ha'amoutolu \\
\hline $3^{\text {rd }}$ & ha'ana & ha'anaua & ha'anautolu \\
\hline Emphatic Possessive ('o) & Singular & Dual & Plural \\
\hline $1^{\text {st }}$ Exclusive & ho'oku & ho'omaua & ho'omautolu \\
\hline $1^{\text {st }}$ Inclusive & ho'ota & ho'otaua & ho'otautolu \\
\hline $2^{\text {nd }}$ & ho'ou & ho'omoua & ho'omoutolu \\
\hline $3^{\text {rd }}$ & ho'ona & ho'onaua & ho'onautolu \\
\hline
\end{tabular}

